\title{
Binaural summation of loudness: Noise and two-tone complexes
}

\author{
LAWRENCE E. MARKS \\ John B. Pierce Foundation Laboratory, New Haven, Connecticut 06519 \\ and Yale University, New Haven, Connecticut 06520
}

\begin{abstract}
A series of six experiments used the method of magnitude estimation to assess how the two ears sum the loudness of stimuli with various spectra. The results showed that the binaural system sums loudnesses by at least two distinct sets of rules, one applicable to narrow-band stimuli (complete loudness summation), another to wide-band noises (partial summation, dependent on level). The main findings were: (1) Narrow-band noise (1/4-octave bands at $1,000 \mathrm{~Hz}$ ) showed complete binaural loudness summation, like that previously reported for pure tones (Marks, 1978a). At all but low SPL, a monaural stimulus must be $10 \mathrm{~dB}$ greater than a binaural stimulus to be equally loud; a stimulus ratio of $10 \mathrm{~dB}$ corresponds to a loudness ratio of $2: 1$ on Stevens' sone scale. (2) Wide-band noise (300-4,800 Hz) showed only partial summation, the subadditivity being confined largely to levels below about $60 \mathrm{~dB}$ SPL. This result obtained both with bands of white noise (flat spectrum) and pink noise $(-3 \mathrm{~dB} /$ octave). (3) Binaural summation of two-tone complexes depended slightly on frequency spacing. Narrow spacing ( 860 and $1,160 \mathrm{~Hz}$ ) gave summation equal to about $10 \mathrm{~dB}$, like that of narrowband noises and single tones, whereas wider spacing $(675$ and $1,475 \mathrm{~Hz})$ gave less summation, equal to about $9 \mathrm{~dB}$, and more like wide-band noise; however, a very wide spacing $(300$ and $4,800 \mathrm{~Hz}$ ) gave summation like that of narrow-band noises and single pure tones.
\end{abstract}

A recent examination (Marks, 1978a) of binaural summation of pure tones provided evidence for a rule of linear addition of loudness. When the method of magnitude estimation was used to scale the loudness of 100-, 400-, and 1,000- $\mathrm{Hz}$ tones, presented at equal or unequal SPL to the two ears, the overall loudness of each stimulus equaled the simple sum of the loudnesses of the components. The scale values of loudness agreed well with Stevens' (1956) sone scale-at $1,000 \mathrm{~Hz}$, loudness increased as about the .6 power of sound pressure.

The major question asked here is: What rules underlie binaural summation of loudness of wideband noise? Reynolds and Stevens (1960) and Scharf and Fishken (1970) concluded that noises are louder when heard binaurally (equal SPL to the two ears) than when heard monaurally, but that the ratio of binaural to monaural loudness increases with increasing SPL. With pure tones, the binaural-monaural ratio is constant (Marks, 1978a; Scharf \& Fishken, 1970; see also Hellman \& Zwislocki, 1963). The finding that binaural summation of the loudness of pure

This research was supported by Grant BNS76-09950 from the National Science Foundation. Ellen Sorman and Sandra Onofrio collected the data in Experiment 1, under the author's direction, as part of a senior research project at Albertus Magnus College. Christine Heselmann helped collect the data in Experiment 4 and David Goldblatt helped collect the data in Experiment 5. Requests for reprints should be sent to Lawrence E. Marks, John B. Pierce Foundation Laboratory, 290 Congress Avenue, New Haven, Connecticut 06519. tones fits a simple additive model prompted this further look at binaural summation of a wide band of white noise, which, in turn, led to an examination of binaural summation of narrow-band noise, wideband pink noise, and two-tone complexes.

\section{EXPERIMENT 1 BINAURAL SUMMATION OF THE LOUDNESS OF WHITE NOISE}

\section{Apparatus and Procedure}

White noise was produced by a Grason-Stadler noise generator (455C), filtered (Allison 2B filter) to a band $300-4,800 \mathrm{~Hz}$, passed through an electronic switch (Grason-Stadler 829C), and split to form two channels, independently attenuated by General Radio attenuators $(1450)$. These signals were led into a sound-attenuated chamber (IAC), where they fed TDH-39 earphones mounted in MX-41/AR sockets. The response of the headphones, calibrated in a Type $9 \mathrm{~A}$ coupler, was flat from 300 to $1,000 \mathrm{~Hz}$, with a dip $(-2 \mathrm{~dB})$ at $2,000 \mathrm{~Hz}$ and a rise $(+4 \mathrm{~dB})$ at $3,000-4,000 \mathrm{~Hz}$. Voltages to the earphones were monitored on a Hewlett-Packard rms voltmeter $(400 \mathrm{~L})$. A Grason-Stadler interval timer (47l), linked to the electronic switch, initiated stimulation and controlled stimulus duration, which was $1 \mathrm{sec}$. Rise and decay times were $10 \mathrm{msec}$.

Two experiments explored overlapping, but nonidentical, portions of the intensity range. In each experiment, nine levels of sound pressure (including a level corresponding to zero intensity) to the left ear combined with the same nine levels to the right ear, making 81 different stimuli in all. Experiment $1 \mathrm{~A}$ explored the range 30-65 dB SPL; Experiment $1 \mathrm{~B}$ explored the range 40-90 dB SPL. Each stimulus was presented and judged twice in the course of an experimental session. Order of presentation of the stimuli was irregular (pseudorandom, in that sequences that contained more than three successive increasing, or decreasing, 
pairs of stimulus levels, which occasionally arise in true random selections, were omitted) and different for each subject.

The method was magnitude estimation. Subjects were instructed to assign to the first stimulus whatever number seemed appropriate to stand for the loudness; then, for succeeding stimuli, they were to assign other numbers in proportion to loudness. If no sound was heard, the subject was to assign the number zero. The subjects were told that the sounds would appear to have various locations, but that apparent location should be disregarded. Each experiment employed 15 young men and women as subjects. All of the subjects in Experiment 1A had had some previous experience making psychophysical judgments, although only 3 had had prior experience judging loudness; 11 of the subjects in Experiment 1B had had previous experience making psychophysical judgments, and 9 of the 11 had had prior experience judging loudness ( 5 of them had served in Experiment 1A).

The makeup of these stimuli and the details of method and procedure were like those used in the study of the binaural summation of the loudness of pure tones (Marks, 1978a).

\section{Results and Discussion}

For the data in each experiment, the magnitude estimates given to each stimulus were averaged geometrically, and these means are plotted in Figures 1 (Experiment 1A) and 2 (Experiment 1B) as a function of the SPL delivered to the right ear. Each contour represents a constant SPL delivered to the left. Note that the loudness estimates are plotted on a linear axis. Comparable data on pure tones obtained by Marks (1978a) showed that the magnitude estimates assigned to a given stimulus equaled the sum of the estimates given to the left-ear and right-ear components individually. Linear additivity implies that the data should yield a set of contours displaced equally from one another in the vertical axis. This is not the case with all of the present data, at least some of which deviate notably from a rule of simple loudness addition.

The standard procedure for evaluating linear addi-

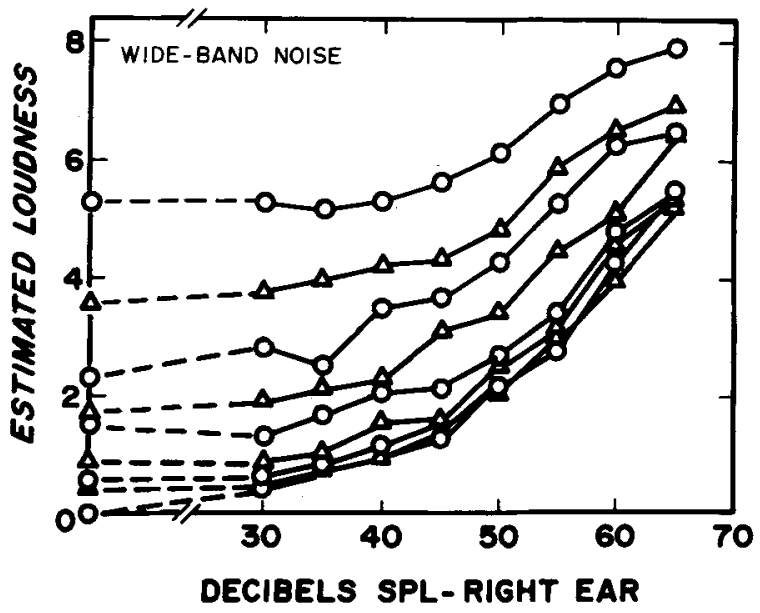

Figure 1. Magnitude estimates of the loudness of white noise $(300-4,800 \mathrm{~Hz})$ as a function of the SPL delivered to the right ear. Each contour represents one of the same noise levels deliv. ered to the left ear. Results of Experiment 1A.

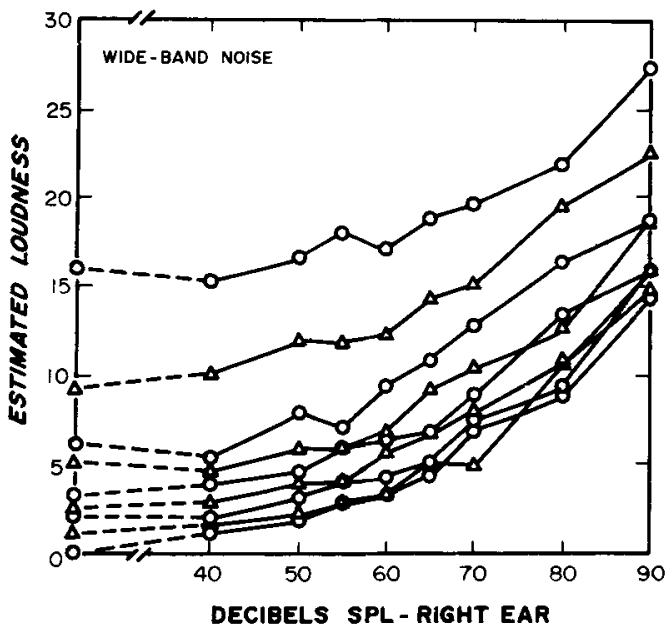

Figure 2. Magnitude estimates of the loudness of white noise $(300-4,800 \mathrm{~Hz})$ as a function of the SPL delivered to the right ear. Each contour represents one of the same noise levels delivered to the left ear. Results of Experiment 1B.

tivity in a data matrix like this is to subject the judgments to analysis of variance (ANOVA) and assess the Stimulus, by Stimulus ${ }_{2}$ interaction (here the Left Ear by Right Ear interaction). Failure of additivity will appear as a significant interaction term (e.g., Anderson, 1970). Legitimate application of ANOVA, however, requires that the data have reasonably uniform variance, a condition that typically does not hold with magnitude estimates. The standard deviations of these magnitude estimates increase nearly in proportion to the means of the estimates. Hence, the results of ANOVA could mislead: It is possible either to miss some small deviations from additivity that might occur at low levels, where the deviations and the variances are relatively small, or to accept improperly some fortuitously large deviations at high levels, where the deviations and their variances are relatively great.

Although straightforward application of ANOVA is questionable, it is possible to derive a related statistical test that is applicable to data with nonuniform variability. Basically, this involves computing an interaction term in which each individual component in it is weighted by its variance. Hence small deviations at low levels, associated with small variance, can contribute as heavily as large deviations at high levels, associated with larger variance. In ANOVA, the value of $F$ is defined as the ratio of the mean squared deviation of the effect tested to the mean squared error. If $D_{i j}{ }^{2}$ represents the squared deviation of the interaction at each stimulus value $i j$, and $V_{i j}$ represents the error variance at $i j$, then the value of $F$ in analysis of variance is defined as

$$
\frac{\Sigma \Sigma D_{i j}{ }^{2} /(N-1)}{\Sigma \Sigma V_{i j} /(N-1)}=\frac{\Sigma \Sigma D_{i j}^{2}}{\Sigma \Sigma V_{i j}}
$$


If, however, each value of $D_{i j}{ }^{2}$ is weighted by its error variance, yielding $D_{i j}{ }^{2} / V_{i j}$, then the mean of the weighted deviations becomes $\mathrm{F}^{*}$, an analogue to $\mathrm{F}$ :

$$
\mathrm{F}^{*}=\frac{1}{\mathrm{~N}} \Sigma \Sigma\left(\frac{\mathrm{D}_{\mathrm{ij}}{ }^{2}}{\mathrm{~V}_{\mathrm{ij}}}\right)
$$

It should be clear that when all values of $\mathrm{V}_{\mathrm{ij}}$ are equal, $F^{*}$ reduces to $F$.

This formula for $\mathrm{F}^{*}$ resembles the extension of the Welch-Aspin test described by Marascuilo (1971). In the latter formulation, however, each value of $D_{i j}{ }^{2}$ is computed as the squared deviation from a weighted grand mean. Such a formulation can be applied directly to analyze main effects; but it cannot be applied to analyze interaction effects, because the latter involve deviations of measured values from sums of row and column values, not from grand means. For the present purposes, the values of $D_{i j}{ }^{2}$ are calculated just as they are in ANOVA. Finally, the use of $\mathrm{F}^{*}$ requires an estimate of the degrees of freedom of the error term ( $\left.\mathrm{df}^{*} \mathrm{error}\right)$ that reflects the variability in $\mathrm{V}_{\mathrm{ij}}$. The estimated $\mathrm{df}^{*}$ error will be smaller than $\mathrm{df}_{\text {error }}$ in ANOVA to the extent that the individual variances are nonuniform (see Marascuilo, 1971, p. 362).

The data of Experiments $1 \mathrm{~A}$ and $1 \mathrm{~B}$ were analyzed by the procedure just outlined. Because the method of free magnitude estimation allows each subject to choose his or her own numerical "modulus," the data were first normalized: Each subject's numbers were multiplied by the constant needed to make that subject's overall mean equal to all the other means. (This is equivalent to eliminating any subject effect and to making the error term the Subject by Stimulus $_{1}$ by Stimulus 2 interaction.) Data of Experiment $1 \mathrm{~A}$ showed a significant overall interaction $\left[F^{*}(63,382)=1.58, p<.01\right]$, but the data of Experiment $1 B$ did not $\left[F^{*}(63,382)=1.02\right.$, n.s.]. Nevertheless, a portion, at least, of the data in Experiment $1 \mathrm{~B}$ do also suggest systematic deviations from linear additivity; these deviations are more readily apparent when the mean estimates are plotted on a logarithmic axis.

Figure 3 plots subsets of the data presented in Figures 1 and 2 . Circles give the average results obtained with monaural stimulation; squares give results obtained with simple binaural stimulation (equal SPLs to the two ears). The dashed line is twice the monaural function, that is, it shows the prediction of an additive model. Plotting the data on a logarithmic axis shows a lack of complete additivity: At low and moderate SPL, the actual loudness judgments of binaural stimuli in both Experiment $1 \mathrm{~A}$ and Experiment $1 \mathrm{~B}$ fall well below the prediction from adding the components. The model of linear additivity can be given a statistical test. Because the variances of the logarithms

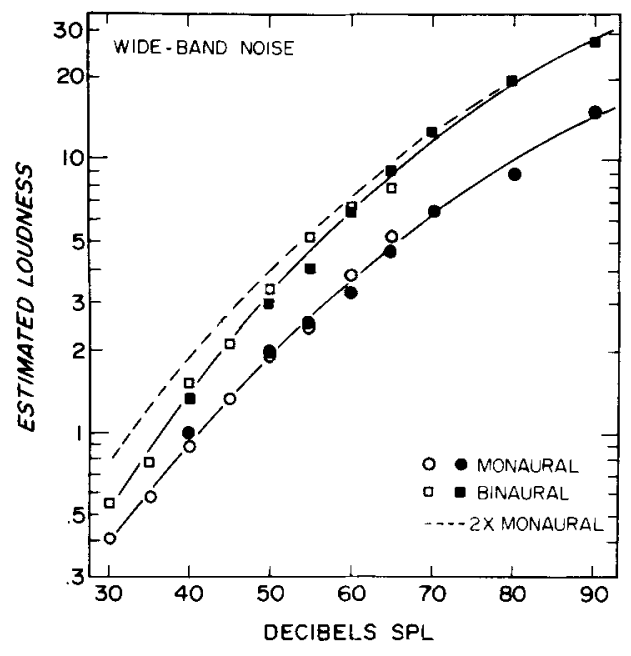

Figure 3. Monaural and binaural loudness functions (wide-band noise) from Experiments $1 A$ (empty symbols) and $1 B$ (filled symbols).

of the magnitude estimates are roughly uniform, ANOVA is applicable. Linear addition implies that the logs of the binaural and monaural functions should be parallel; nonparallelism implies a significant interaction between stimulus level and condition (monaural vs. binaural). The interaction was significant in Experiment $1 \mathrm{~B}[\mathrm{~F}(7,224)=2.07 ; \mathrm{p}<.05]$, and though not quite significant in Experiment 1A $[F(7,224)=1.47, .25<p<.10]$, the trend goes in the same direction, as Figure 3 shows. At low SPL, binaural summation of the loudness of white noise is partial, not complete. At higher SPL (above about $60 \mathrm{~dB}$ ), however, these data show summation to be just about perfect. In general, agreement between the two studies is good; their results concur in pointing to relatively smaller amounts of summation at low stimulus levels.

Binaural summation of the loudness of wide-band noise seems to differ from summation of pure tones. Scharf and Fishken (1970) used magnitude estimation and magnitude production to compare monaural and binaural loudness functions for a $1,000-\mathrm{Hz}$ tone and for white noise. Although their results with a $1,000-\mathrm{Hz}$ tone showed less than perfect binaural summation, the amount of summation (ratio of binaural to monaural loudness) was constant over a wide range of SPLs, as it was in the study by Marks (1978a). In both of those studies, the loudness of a $1,000-\mathrm{Hz}$ tone grew as a power function of sound pressure (exponent .5 in Scharf and Fishken's study, .6 in Marks'). By contrast, the psychophysical functions for noise, both in the present study and in Scharf and Fishken's, are not power functions of sound pressure; in double logarithmic coordinates, the functions are curved over a wide range of SPL (a finding common with wide-band noise, e.g., Pollack, 
1951; Scharf \& Fishken, 1970; Zwicker, Flottorp, \& Stevens, 1957; Zwicker \& Scharf, 1965). And both studies show that, when plotted in log-log coordinates, the psychophysical functions for monaural and binaural listening diverge. Reynolds and Stevens (1960) also concluded that monaural and binaural loudness functions diverge. Reynolds and Stevens, however, described both curves as simple power functions (straight lines in log-log coordinates). This means that the ratio of binaural to monaural loudness would increase continuously with increasing SPL. The present data, on the other hand, suggest that, above about 60 or $70 \mathrm{~dB}$ SPL, the ratio of binaural to monaural loudness may be constant and about equal to 2:1.

A striking characteristic of the binaural and monaural functions, as shown in Figure 3, is the systematic change in the number of decibels separating them. Results of Irwin (1965), Reynolds and Stevens (1960), Scharf (1968), and Scharf and Fishken (1970), show a similar change with level. At low levels, the monaural noise must be about $3 \mathrm{~dB}$ greater than the binaural noise in order to be judged as loud, but this difference increases to about $14 \mathrm{~dB}$, in the present set of data, at levels above $70 \mathrm{~dB}$. By way of contrast, data on pure tones collected under analogous conditions (Marks, 1978a) showed a decibel difference that quickly rose from about $3 \mathrm{~dB}$ near threshold to about $10 \mathrm{~dB}$ at stimulus levels $20 \mathrm{~dB}$ above threshold, and remained roughly constant from there on.

The following series of experiments sought to compare the relations between binaural and monaural loudness functions in wide-band and narrow-band signals. In order to evaluate these relationships, binaural summation of wide-band white noise was compared with summation of narrow-band noise. A noise of sufficiently narrow bandwidth should behave much like a pure tone (Zwicker \& Scharf, 1965). Jankovic and Cross (Note 1) used the method of magnitude estimation to study binaural summation of the loudness of narrow-band noise (center frequency, $3,150 \mathrm{~Hz}$ ), and their results are consistent with data obtained by Marks (1978a) with pure tones. Scharf (1968) used a matching procedure to compare binaural summation of a $1,000-\mathrm{Hz}$ tone, criticalband noise, octave-band noise, and wide-band noise. Narrow-band noise and pure tone gave similar results - constant summation, in decibels, at levels above about $40 \mathrm{~dB}$ SPL. Wider bands of noise, however, showed summation, in decibeis, to increase as SPL increased.

The first of the experiments that follow evaluates the binaural summation of a narrow-band noise. Subsequent experiments compare directly monaural and binaural loudness functions for wide-band and narrow-band noises.

\section{EXPERIMENT 2 BINAURAL SUMMATION OF THE LOUDNESS OF NARROW-BAND NOISE}

\section{Apparatus and Procedure}

The production of the stimuli was identical to that used in the previous experiments, except that the low-pass and high-pass of the filter were set to give a narrow band (approximately $1 / 4$ octave) centered at $1,000 \mathrm{~Hz}$. The slopes of the filters at both the low and high ends were measured at $30 \mathrm{~dB} /$ octave. The method again was magnitude estimation. Each of 15 new subjects (nearly all of whom had had some previous experience making psychophysical judgments, though only 3 had had prior experience in judging loudness) judged the loudness of each of 81 different combinations of sound pressure (zero intensity, plus SPLs from 25 to $60 \mathrm{~dB}$ ) to the two ears. Each stimulus was presented and judged twice in the course of a session.

\section{Results and Discussion}

Geometric means of the magnitude estimates of loudness appear in Figure 4. The data come close to agreeing with a simple additive model, but fall slightly short of perfect additivity. In general, the estimates given to binaural stimuli are a bit smaller than the values predicted by summing the estimates given to the left-ear and right-ear components. The Left Ear

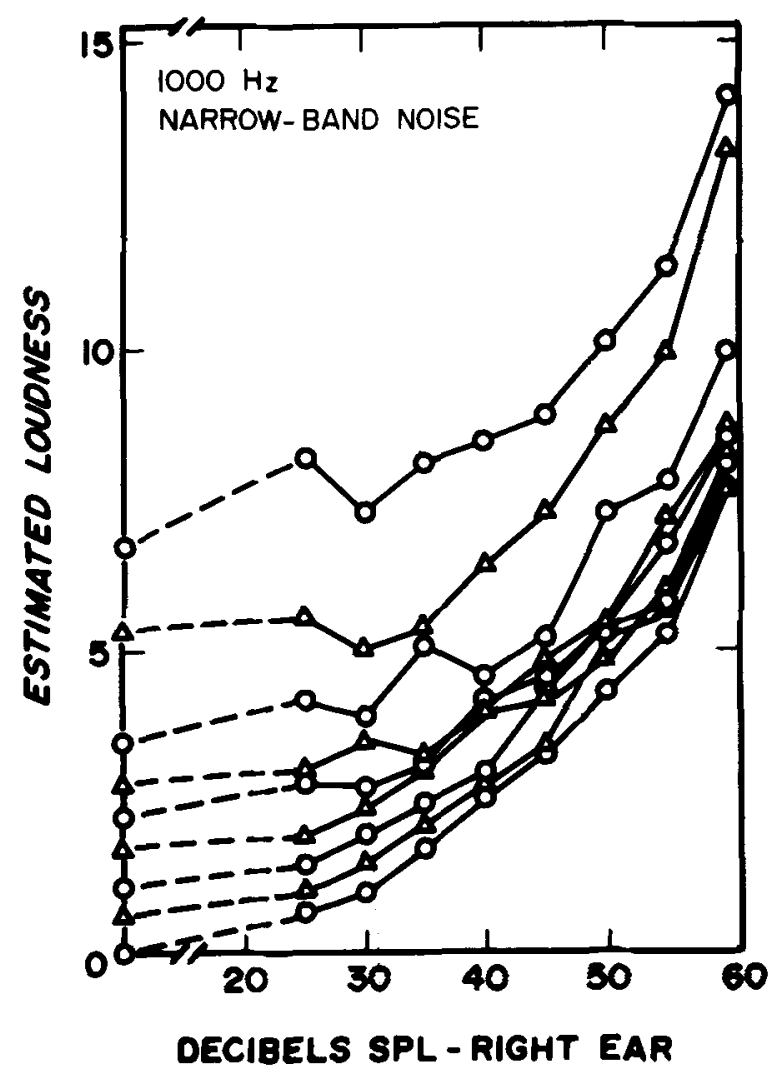

Figure 4. Magnitude estimates of the loudness of narrow-band noise as a function of the SPL delivered to the right ear. Each contour represents one of the same noise levels delivered to the left ear. Results of Experiment 2. 


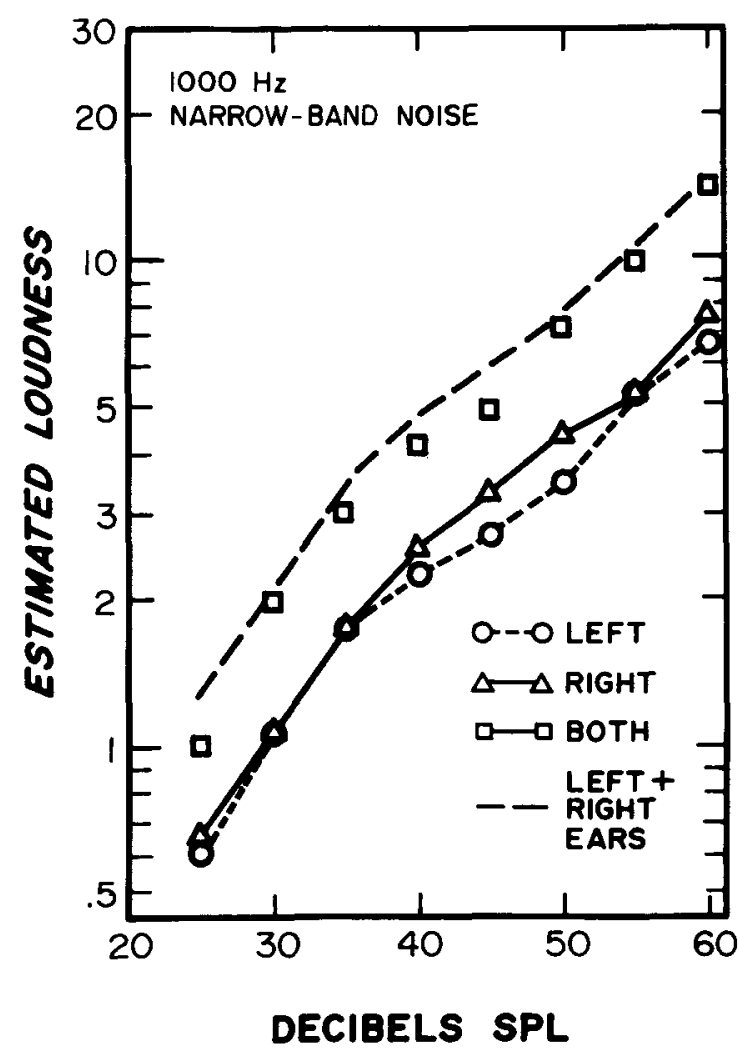

Figure 5. Magnitude estimates of the loudness of binaural (equal SPL) and monaural narrow-band noises. These data are subsets of the data in Figure 4 (Experiment 2).

by Right Ear interaction is significant: $F^{*}(63,382)=$ $1.67, \mathrm{p}<.01$. Figure 5 , which plots results for monaural and simple binaural (equal SPL) stimulation, makes this clear. Three points are noteworthy. First, the slight subadditivity is constant throughout the intensity range, unlike the results obtained with wideband noise. In logarithmic coordinates, the monaural and binaural functions are wholly parallel $[F(7,224)$ $<1$, n.s.]. Second, the decibel difference separating binaural and monaural functions rises quickly from about $4 \mathrm{~dB}$ at the lowest stimulus level to about $10 \mathrm{~dB}$, after which it remains fairly constant throughout. This behavior also characterizes results obtained with pure tones (Marks, 1978a). Third, over all but the lowest levels of SPL, the loudness functions approximate straight lines-power functions of sound pressure with exponents equal to about $\mathbf{4 6}$. This value is notably smaller than the .6 obtained with pure tones, and its reduced size probably represents an example of what Stevens and Greenbaum (1966) called "regression"- the constriction by the subjects of the range of response. This "regression" is not easily accounted for. The analogous experiment using pure tones gave much less "regression"; the power-function exponent at $1,000 \mathrm{~Hz}$ was .6 (Marks, 1978a). On the other hand, an unpublished study of binaural summation of a $1,000-\mathrm{Hz}$ tone, conducted in this laboratory by Marc Sebrechts and described by Marks (1979), evidenced considerable "regression"; the exponent there was .3.

Jankovic and Cross' study of binaural summation with narrow-band noise had an outcome similar to that of the present experiment. Jankovic and Cross combined each of six left-ear components (zero intensity, plus SPLs from 40 to $80 \mathrm{~dB}$ ) with each of the same six right-ear components and had subjects give magnitude estimates of loudness. The monaural and binaural (equal SPL) functions followed an exponent of .47 , and gave a little less than complete summation. Jankovic and Cross showed that their results could be made to display full loudness additivity by subjecting the data to a mild power transformation, one sufficient to raise the exponents of the power functions to about .6. An exponent of .6 means that loudness doubles with every $10-\mathrm{dB}$ increase in stimulation. Because $10 \mathrm{~dB}$ separate binaural from monaural functions, it follows that going from monaural to binaural stimulation is like augmenting the stimulus by $10 \mathrm{~dB}$, or like doubling the loudness. (Rescaling magnitude estimates of loudness so as to bring the exponent to .6 also revealed additive effects in measuring the loudness of multicomponent tones; Marks, 1978b, 1979.)

If the present data are rescaled by a power transformation with exponent 1.3, which serves to increase the exponent of the power function to .60 , the rescaled data evidence complete loudness additivity and the loudness scales themselves now agree both with Stevens' sone scale and with Marks' previous results on binaural summation for pure tones. In terms of binaural summation, therefore, narrow-band noise appears to behave identically to pure tone. This raises the question, however, of whether the lack of complete additivity found with wide-band noise (Experiment 1) might also represent some sort of numerical response bias and the data be rescalable to full additivity. The next experiment sought to compare directly binaural summation of wide- and narrow-band noises.

\section{EXPERIMENT 3 \\ WIDE- AND NARROW-BAND NOISE: BINAURAL SUMMATION COMPARED}

\section{Apparatus and Procedure}

In Experiment 3, the stimulus set included only monaural stimuli and binaural stimuli of equal SPL to the two ears. Two experiments were run, exploring largely overlapping ranges of intensity. Experiment 3 used wide- and narrow-band stimuli over the range 25-60 dB SPL; Experiment 3 used wide-band stimuli over the ranges 25-60 dB (monaural) and 30-60 dB (binaural) and narrowband stimuli over the ranges 25-70 dB (monaural) and 30-70 dB (binaural). Left-ear, right-ear, and binaural presentations of wideband and narrow-band noises (the same bandwidths used in the previous experiments) at different levels of SPL were interspersed 
within a given session in order to make the results directly comparable; the subjects gave magnitude estimates of the loudness. (This design parallels that of Scharf and Fishken, 1970, who used magnitude estimation and production to compare directly the summation of wide-band noise and $1,000-\mathrm{Hz}$ tone.) In each part of the experiment, every stimulus was presented and judged twice in the course of a session by each of 12 subjects. All had had previous experience making psychophysical judgments, but only 1 subject in Experiment 3A and 4 subjects in Experiment 3B had had prior experience judging loudness ( 3 of the latter were subjects who had served in Experiment 3A).

\section{Results and Discussion}

Geometric means of the magnitude estimates obtained in the two experiments are plotted in Figure 6. Unfilled symbols show results from Experiment 3A; filled symbols show results from Experiment 3B. The experiments gave similar results: With narrow-band noise, the binaural and monaural loudness functions, when plotted on log-log coordinates, are parallel. Binaural loudness bears a constant ratio to monaural loudness; again, however, the ratio is slightly smaller than $2: 1$, an outcome directly related to the relatively low exponent of the power function-about .43. But, again, the decibel difference (at all but very low SPL) separating the binaural and monaural functions is constant at $10 \mathrm{~dB}$; if "regression" is eliminated by transforming the data according to a power function sufficient to increase the exponent of the loudness function to .6, the rescaled data show perfect loudness summation.

Wide-band noise behaved differently. For one, the psychophysical functions are bow-shaped throughout their range (25-60 dB SPL), a curvature that has been noted several times before (Pollack, 1951; Scharf \& Fishken, 1970; Zwicker et al., 1957). Second, over the range of SPL explored in these experiments, summation was not only less than perfect, but less than the summation obtained with narrow-band noise. Wideband noise gave a ratio of binaural to monaural loudness equal on the average to $1.5: 1$, whereas narrowband noise gave an average ratio equal to $1.65: 1$. The difference in loudness summation is statistically reliable. Analysis of variance, computed on the logarithms of the ratios of binaural to monaural loudness judgments, showed a significant effect of condition (narrow vs. wide band) in both Experiments $3 \mathrm{~A}$ and $3 \mathrm{~B}[\mathrm{~F}(1,176)=120.8, \mathrm{p}<.001$, and $\mathrm{F}(1,154)=$ $82.3, \mathrm{p}<.001$, respectively]. Note, too, that the decibel difference separating the binaural and monaural functions in Figure 6 is smaller for wide-band noise, where this difference increases gradually from about $3 \mathrm{~dB}$ to about $8 \mathrm{~dB}$ over the range 25 to $60 \mathrm{~dB}$ SPL. This resembles the findings of Scharf (1968) and Scharf and Fishken (1970). If the data obtained for wide-band noise are rescaled along with the data for narrow-band noise, the wide-band data still show less than perfect binaural summation of loudness. The ratio of binaural to monaural loudness becomes

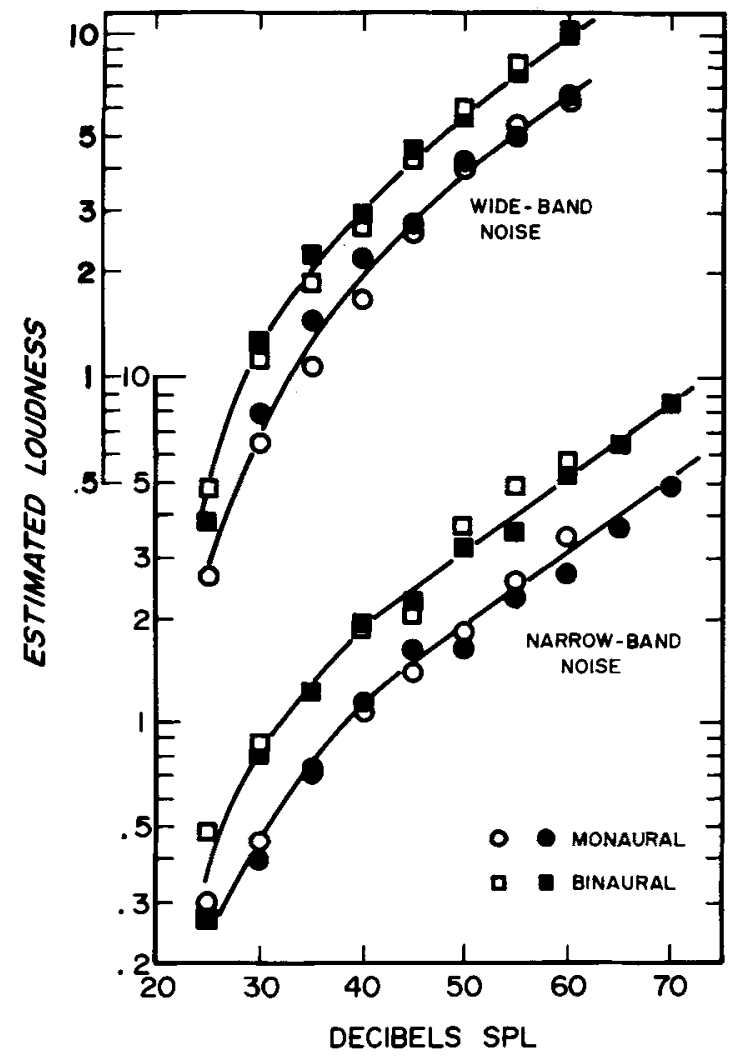

Figure 6. Magnitude estimates of the loudness of binaural (equal SPL) and monaural stimuli. The upper set of functions gives results for a band of white noise $(300-4,800 \mathrm{~Hz})$; the lower set gives results for a narrow band of noise centered on $1,000 \mathrm{~Hz}$. Results of Experiments $3 A$ funfilled symbols) and 3B (filled symbols).

about $1.75: 1$ for wide-band noise when it is $2: 1$ for narrow-band noise.

\section{EXPERIMENT 4 \\ BINAURAL SUMMATION OF LOUDNESS OF PINK NOISE}

The wide-band noise used in Experiments 1 and 3 had a relatively flat spectrum over the frequency range explored $(300-4,800 \mathrm{~Hz})$. The auditory system, however, is not flat in its response; instead, auditory threshold declines with increasing frequency over this range. This means that, at very low levels (near threshold), the auditory system presumably responds only to the high-frequency portion of the white noise and, as the level increases, the system responds to more and more of the lower frequencies. Experiment 4 examined binaural summation of loudness for a wide-band noise whose spectrum more closely matched the auditory system's threshold function.

\section{Apparatus and Procedure}

The apparatus was the same as that of Experiment 3, with one addition: In producing wide-band noise, a single-stage low-pass 
filter was inserted between the low $(300 \mathrm{~Hz})$ and high $(4,800 \mathrm{~Hz})$ frequency cutoff filters. This additional filter served to shape the noise's spectrum by decreasing the spectrum level about $3 \mathrm{~dB} /$ octave; that is, the filter turned the band of white noise into, approximately, a band of pink noise.

The set of stimuli comprised wide-band pink noises ranging from $25-70 \mathrm{~dB}$ SPL in steps of $5 \mathrm{~dB}$, delivered to the left ear, right ear, and binaurally (equal SPL to the two ears). Each stimulus was presented and judged (by magnitude estimation) twice in the course of a session by each of 16 subjects (all with some previous experience in making psychophysical judgments, 4 of them with prior experience in judging loudness, having served in Experiment 3B). To provide a control, the subjects also judged the loudness of an analogous set of narrow-band noises (1/4-octave bands at $1,000 \mathrm{~Hz}$ ) at the same SPLs. Eight of the subjects judged pink noises first, then white noises; the other eight subjects judged them in the reverse order.

\section{Results and Discussion}

Figure 7 plots geometric means of the magnitude estimates. The data obtained with narrow-band noise (lower portion of the figure) are roughly in accord with the results obtained in Experiments 2 and 3. Over much of the range, $10 \mathrm{~dB}$ separate the monaural and binaural functions (actually, the separation increases from about $4 \mathrm{~dB}$ at the lowest levels to about

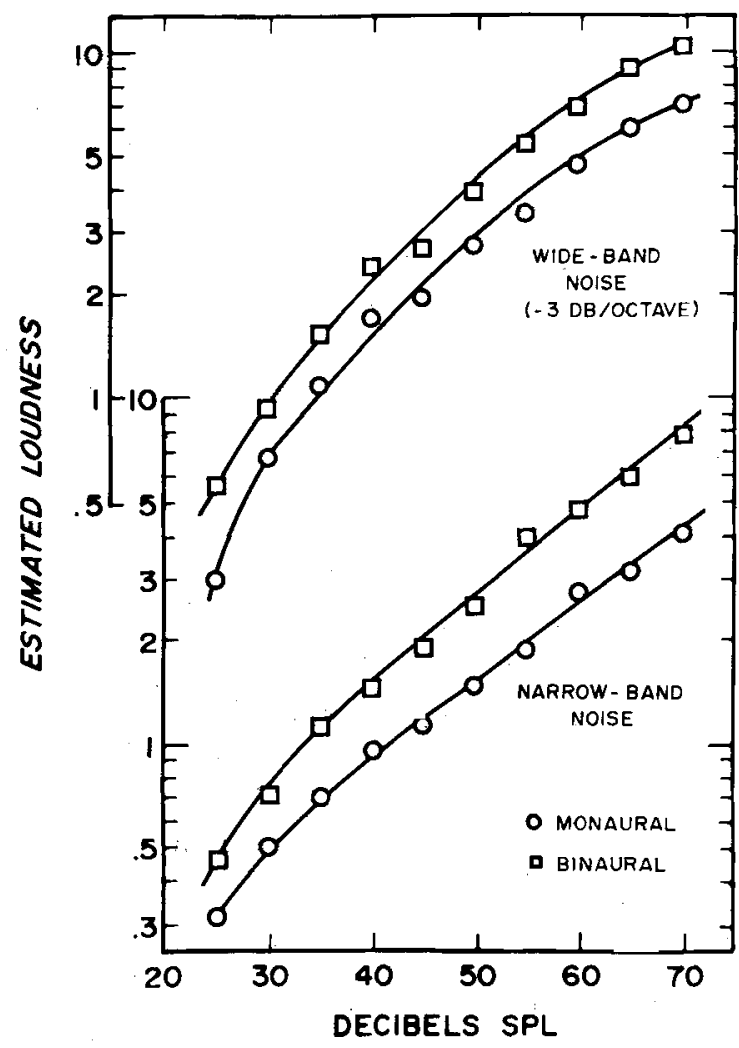

Figure 7. Magnitude estimates of the loudness of binaural (equal SPL) and monaural stimuli. The upper set of functions gives results for a band of pink noise $(300-4,800 \mathrm{~Hz},-3 \mathrm{~dB} /$ doubling of frequency); the lower set gives resulis for a narrow band of noise centered on 1,000 Hz. Results of Experiment 4.
$10 \mathrm{~dB}$ at medium levels and to about $12 \mathrm{~dB}$ at the highest levels). The ratio of monaural to binaural loudness averages about 1.8:1; this value is again smaller than the $2: 1$ ratio predicted by perfect loudness summation, probably again because the slopes (exponents) of the loudness functions are only about .5 instead of .6 .

The data obtained with wide-band pink noise (upper portion of Figure 7) show the same two features that characterize data obtained with wide-band white noise: (1) considerable curvature (bowing) in the shapes of the psychophysical functions, as Zwicker and Feldtkeller (1967) previously noted, and (2) markedly less binaural summation than that shown by narrow-band noise. In the present data, the ratio of binaural to monaural loudness averages about 1.4:1. The difference between the summation ratios for wide- and narrow-band noises is again statistically significant $[F(1,300)=201.5, p<.001]$. One characteristic of the data on pink noise (Figure 7) is virtually identical to that for the data on white noise (Figure 6): The separation between the monaural and binaural functions increases gradually and steadily from about $3 \mathrm{~dB}$ at the lowest levels to about $8 \mathrm{~dB}$ at an SPL of $60 \mathrm{~dB}$. That is to say, these data suggest that a single rule underlies binaural summation of both types of wide-band noise (while another rule underlies summation of pure tones and narrowband noise). Except perhaps that pink noise yields even less summation than does white noise, no obvious property distinguishes the way the auditory system sums binaurally the loudness of these two types of wide-band noise.

\section{EXPERIMENT 5 \\ BINAURAL SUMMATION OF LOUDNESS OF TWO-TONE COMPLEXES}

The binaural system operates differently on wideband noises and on narrow-band signals. The question arises as to whether the properties that characterize summation of wide-band noise emerge with other sorts of wide-band stimuli, such as multicomponent tones. Scharf (1968) used a loudness-matching procedure to measure binaural summation of threetone complexes with small and large overall frequency spacings. The large spacing yielded summation, in decibels, that increased with increasing SPL, just as Scharf found with wide-band noise. The present experiment was an attempt to determine whether a two-tone complex, like wide-band noise, displays imperfect binaural summation as measured in loudness units.

\section{Apparatus and Procedure}

Sinusoidal signals from four oscillators (three General Radio 1210 and one Heath-Schlumberger SG72-A provided pure-tone 
signals. Each sinusoid could be amplified and attenuated independently, before combining at a mixer. The output of the mixer was gated and timed to produce $1-\mathrm{sec}$ stimuli with rise and decay times of $10 \mathrm{msec}$.

Two different two-tone combinations came under investigation: A complex with relatively narrow spacing $(\Delta f)$ between components (consisting of frequencies of 860 and $1,160 \mathrm{~Hz}$ ) and a complex with relatively wide spacing between components $(675$ and $1,475 \mathrm{~Hz}$ ). The geometric center frequency of both pairs equals $1,000 \mathrm{~Hz}$. Left-ear, right-ear, and binaural presentations of both complexes, at various values of SPL, were interspersed within a given session in order to make the results directly comparable. Again, the method was magnitude estimation. Each stimulus was presented and judged twice by each of 16 subjects, most of whom had had previous experience in making psychophysical judgments, and 3 of whom had had prior experience in judging loudness.

\section{Results and Discussion}

Figure 8 gives the results. Binaural summation was similar, but not identical in the two complexes. The complex with the smaller $\Delta \mathrm{f}(860$ and $1,160 \mathrm{~Hz})$ gave about $10 \mathrm{~dB}$ of summation throughout most of the stimulus range, an average binaural-to-monaural loudness ratio of $1.60: 1$, and an exponent of .40 , whereas the complex with the wider $\Delta \mathrm{f}(675$ and $1,475 \mathrm{~Hz}$ ) gave a bit less summation, equal to about $9 \mathrm{~dB}$, with an average binaural-to-monaural loudness ratio of $1.51: 1$ and an exponent of .43 . The difference between the binaural-monaural loudness ratios

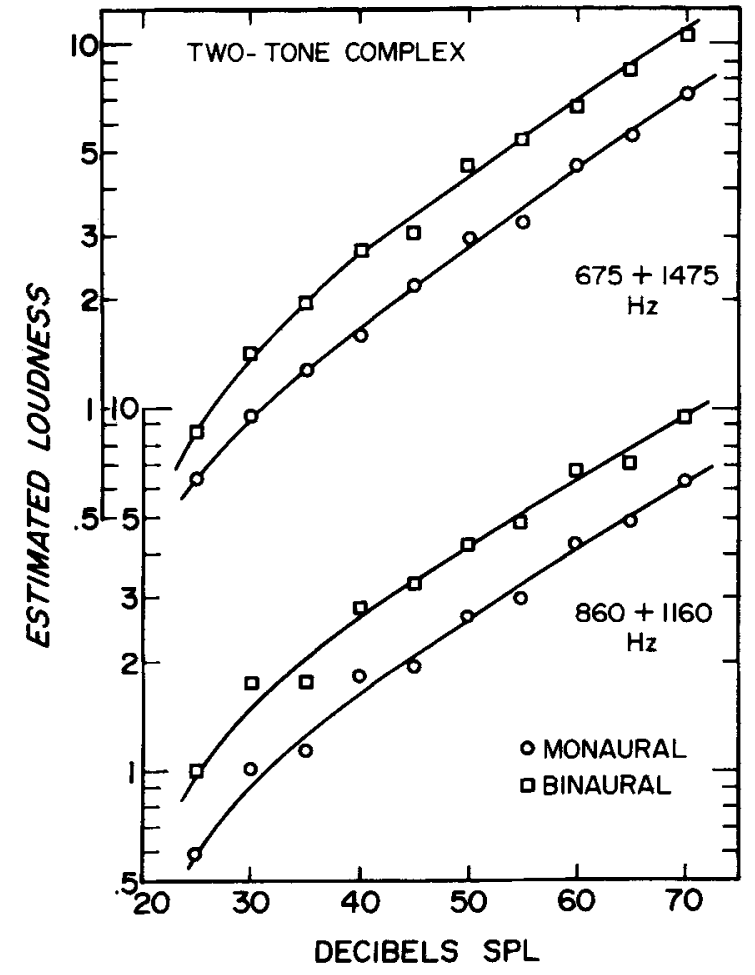

Figure 8. Magnitude estimates of the loudness of binaural (equal SPL) and monaural stimuli. The stimuli were two-tone combinations, either 675 and $1,475 \mathrm{~Hz}$ (upper functions) or 860 and $1,160 \mathrm{~Hz}$ (lower functions). Results of Experiment 5. is significant $[\mathrm{F}(1,300)=155.5, \mathrm{p}<.001]$. Thus, the binaural summation measured with the wider "bandwidth," $675+1,475 \mathrm{~Hz}$, is consistently smaller than that measured with the narrower "bandwidth," $860+1,160 \mathrm{~Hz}$, and smaller than the values obtained with single pure tones at $1,000 \mathrm{~Hz}$ (Marks, 1978a) and with narrow-band noise (present Experiments 2-4); while the narrower bandwidth gave binaural summation like that characterizing narrowband stimuli, the wider bandwidth gave summation intermediate between those characterizing narrowband and wide-band stimuli.

\section{EXPERIMENT 6 ONE AND TWO TONES: BINAURAL SUMMATION COMPARED}

This final experiment is an analogue, using pure tones, to Experiments 3 and 4 on noise: Experiment 6 compared directly the binaural summation of a single tone (at $1,000 \mathrm{~Hz}$, analogous to the narrow-band noise) to the binaural summation of a complex comprising two widely spaced tones (at 300 and $4,800 \mathrm{~Hz}$, equal to the cutoff frequencies of the wide-band noise). Given the results of Experiment 5, which suggested that the complex with the wider spacing showed reliably less binaural summation than did the complex with the narrower spacing, it is possible that a two-tone complex with a very wide frequency separation would give even less summation, and hence behave yet more like a wide-band noise. If the binaural summation of two widely separated tones differs from the summation of a single tone, a significant conclusion would follow-namely that the summation of loudness across sound frequency would obey different rules under monaural and binaural listening conditions.

\section{Apparatus and Procedure}

The outputs of two oscillators combined at a mixer to produce the $300+4,800 \mathrm{~Hz}$ complex, and the output of a third oscillator produced the single pure tone at $1,000 \mathrm{~Hz}$. The single, $1,000-\mathrm{Hz}$ tone was presented at each of $10 \mathrm{SPLs}$ from 25 to $70 \mathrm{~dB}$. In the complex, the $4,800-\mathrm{Hz}$ component was presented at each of the same 10 SPLs, 25-70 dB; combined with each SPL of the $4,800-\mathrm{Hz}$ component was the $300-\mathrm{Hz}$ component set $13 \mathrm{~dB}$ higher, that is, at levels from 38 to $83 \mathrm{~dB}$. The levels of the 300 - and $4,800-\mathrm{Hz}$ tones were preselected so that the components in each complex would be about equally loud, and so that each would be about as loud as the corresponding 1,000-Hz tone.

Left-ear, right-ear, and binaural presentations of the single tones and the tone pairs were interspersed within a given session, and the subjects again made magnitude estimations of loudness. Each stimulus was presented and judged twice in the course of a session by each of 16 subjects; most had no previous experience making psychophysical judgments, and only four had previous experience judging loudness. Because of the great frequency separation between the components of the complex, special attention was paid to inform the subjects that some stimulus presentations contained pairs of tones, and to instruct the subjects to judge the overall loudness of each compound stimulus. 


\section{Results and Discussion}

The results appear in Figure 9. The sole salient difference between the data obtained with the single tones and with the tone pairs appears in the forms of the loudness functions. The single tones yielded straight lines, which is to say power functions (average exponent of .46), whereas the tone pairs yielded markedly bowed functions. In terms of the binaural summation, however, there is little indication of any difference: The average binaural-monaural loudness ratio is $1.70: 1$ for the $1,000-\mathrm{Hz}$ tone, $1.72: 1$ for the $300+4,800 \mathrm{~Hz}$ complex, an insignificant difference $[F(1,300)<1]$. Although the data hint at some slight difference between results with one and two tonesin that the binaural-monaural ratio increases slightly with increasing SPL of the single tone, but decreases slightly with increasing SPL of the two tones-this difference is not reliable; neither the overall interaction nor the bilinear component of the interaction (which measures divergence) is significant $[F(9,300)$ and $F(1,300)$, respectively, both $<1]$. In sum, the two stimuli-1,000-Hz tone, $300+4,800 \mathrm{~Hz}$ complex -appear virtually identical in their binaural summation of loudness.

As already mentioned, there is a notable difference in the form of the function relating the loudness esti-

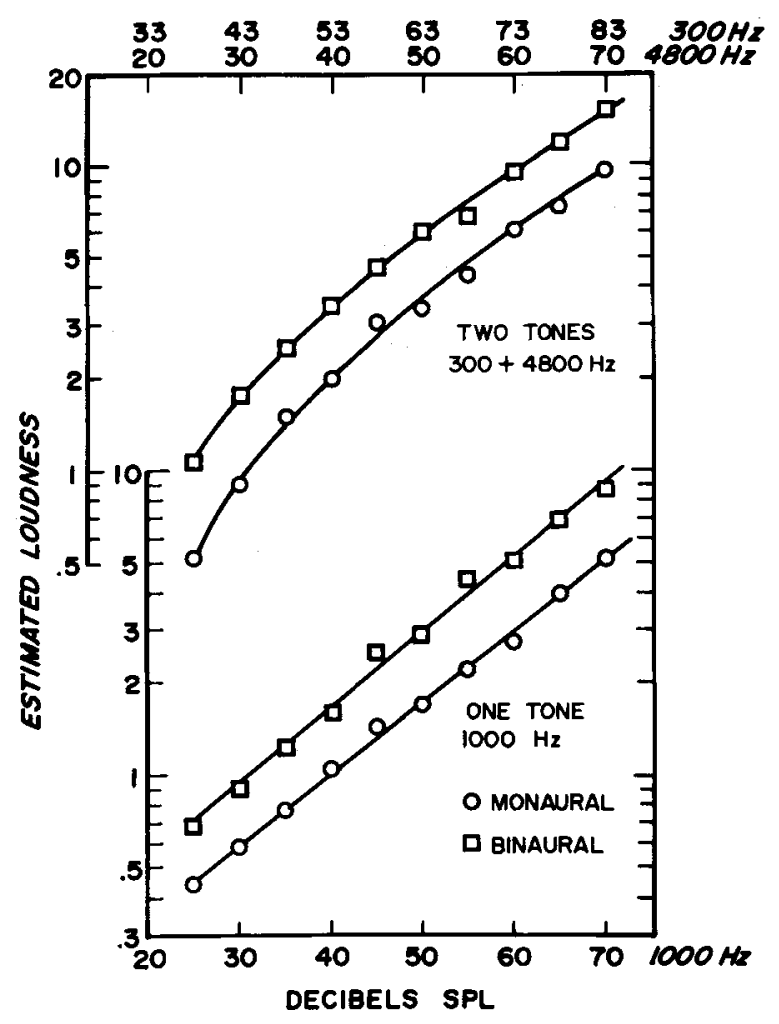

Figure 9. Magnitude estimates of the loudness of binaural (equal SPL) and monaural stimuli. The stimuli were two-tone complexes of 300 and $4,800 \mathrm{~Hz}$ (upper functions) or single pure tones of 1,000 $\mathrm{Hz}$ (lower functions). Results of Experiment 6. mates to SPL. The curvature in the function for the $300+4,800 \mathrm{~Hz}$ complex could have either or both of two sources: (1) bowing often appears in loudness functions for supercritical multitone complexes (e.g., Zwicker et al., 1957); and (2) bowing often appears in loudness functions measured at low sound frequencies (e.g., Hellman \& Zwislocki, 1968). The latter is the more likely to be the basis for the present results. The frequency separation between 300 and $4,800 \mathrm{~Hz}$ should be sufficient to permit simple loudness summation between these components themselves. (Note that the monaural function for the complex is on the average at about the same level as the binaural function for the single tone; this agreement is consistent with linear loudness summation within the complex, given that each of the two components was on the average as loud as the corresponding $1,000-\mathrm{Hz}$ tones.) If the components of the two-tone complex summed their loudnesses linearly, then the loudness function would represent the linear sum of the loudness functions of the components. Most likely, the bowed shape represents curvature in the loudness function of the $300-\mathrm{Hz}$ component. This was previously found to be the case with two-tone complexes, heard binaurally, made up of components at 300 and $1,000 \mathrm{~Hz}$ (Marks, 1979).

\section{GENERAL DISCUSSION}

The binaural system sums loudnesses according to at least two different sets of rules. When the stimulus energy falls within a narrow range of frequencies (pure tone, narrow-band noise)-and, under some conditions, when it comprises pairs of pure tonesthe rule is one of simple addition of loudness components from the left and right ears. When the stimulus is wide-band noise, however, the rules are more complicated, giving partial summation at low SPL, increasing to greater summation at high SPL.

Treisman and Irwin (1967) proposed a multistage model for binaural summation of wide-band noise. According to this model, the noise stimuli to the two ears produce internal sensory effects that do sum linearly; however, the summed outputs are subsequently transformed by a nonlinear function, thereby creating a nonadditivity. Still, there is the question: Why do different processes apply to wide-band noises and to narrow-band signals?

It is puzzling that the degree of summation of wide-band noise should differ from that of narrowband signals and that it should increase with level. Why should the spectral distribution of the sound energy matter to the way the binaural system sums loudnesses? And, given that it does matter, why should it matter most at lowest intensities? Whatever the reason, it has several consequences. For one, it means that the way the loudness of a noise increases with increasing bandwidth is not the same with binaural and with monaural listening. 
That the rule of binaural loudness summation depends on the frequency relationships among the components suggests that the rule of binaural summation relates to the rule of loudness summation across frequency: (1) Narrow-band noises, pure tones, and pairs of tones with relatively narrow frequency spacing give essentially complete binaural summation; when overall spacing is small (less than a critical bandwidth), loudness, across frequency, depends on the total energy of the components (e.g., Zwicker et al., 1957). (2) Pairs of tones with very large frequency spacing also give complete binaural summation; when overall spacing is great, loudness, as summed across frequency, equals the sum of the individual loudnesses of the components (see Marks, 1979, for review). (3) Wide-band noises and pairs of tones with intermediate frequency spacing give less than full binaural summation; the overall loudness of such signals, across frequency, follows a rule that presumably combines both energy summation and loudness summation (e.g., Zwicker \& Scharf, 1965). Just how the rules of energy summation and loudness summation are combined depends on whether the noise or multicomponent tone is heard with one or two ears, and therefore presumably depends on central as well as peripheral processes.

\section{REFERENCE NOTE}

1. Jankovic, I. N., \& Cross, D. V. On the binaural additivity of loudness. Paper presented at the meeting of the Eastern Psychological Association, Boston, April 1977.

\section{REFERENCES}

Anderson, N. H. Functional measurement and psychophysical judgment. Psychological Review, 1970, 77, 153-170.

Hellman, R. P., \& Zwislocki, J. J. Monaural loudness function at $1,000 \mathrm{cps}$ and interaural summation. Journal of the Acoustical Society of America, 1963, 35, 856-865.
Hellman, R. P., \& Zwislocki, J. J. Loudness determination at low sound frequencies. Journal of the Acoustical Society of America, 1968, 43, 60-64.

IRWIN, R. J. Binaural summation of thermal noises of equal and unequal power in each ear. American Journal of Psychology, $1965,78,57-65$.

Marascuilo, L. A. Statistical methods for behavioral science research. New York: McGraw-Hill, 1971.

Marks, L. E. Binaural summation of the loudness of pure tones. Journal of the Acoustical Society of America, 1978, 64, 107-113. (a)

MARKS, L. E. PHONION: Translation and annotations concerning loudness scales and the processing of auditory intensity. In N. J. Castellan, Jr., \& F. Restle (Eds.), Cognitive theory (Vol. 3), Hillsdale, N.J: Erlbaum, 1978. (b)

Marks, L. E. A theory of loudness and loudness judgments. Psychological Review, 1979, 86, 256-285.

Pollack, I. On the measurement of the loudness of white noise. Journal of the Acoustical Society of America, 1951, 23, 654-657.

Reynolds, G. S., \& Stevens, S. S. Binaural summation of loudness. Journal of the Acoustical Society of America, 1960, 32, 1337-1344.

SchARF, B. Binaural loudness summation as a function of bandwidth. In Y. Kohasi (Ed.), Reports of the 6th International Congress on Acoustics (Vol. 1). Tokyo: Marazen A-3-5, 1968.

Scharf, B., \& Fishken, D. Binaural summation of loudness: Reconsidered. Journal of Experimental Psychology, 1970, 86, 374-379.

Stevens, S. S. The direct estimation of sensory magnitudesloudness. American Journal of Psychology, 1956, 69, 1-25.

Stevens, S. S., \& Greenbaum, H. B. Regression effect in psychophysical judgment. Perception \& Psychophysics, 1966, 1, 439-446.

Treisman, M., \& Irwin, R. J. Auditory intensity discriminal scale. 1. Evidence derived from binaural intensity summation. Journal of the Acoustical Society of America, 1967, 42, 586-592.

Zwicker, E., \& Feldtkeller, R. Das Ohr als Nachrichtenempfänger. Stuttgart: Hirzel, 1967.

Zwicker, E., Flottorp, G., \& Stevens, S. S. Critical band width in loudness summation. Journal of the Acoustical Society of America, 1957, 29, 548-557,

ZWicker, E., \& Scharf, B. A model of loudness summation. Psychological Review, 1965, 72, 3-26.

(Received for publication December 10, 1979; accepted March 6, 1980.) 